\title{
A BIM-driven framework for integrating rules and regulations in the decommissioning of nuclear power plants.
}

\section{Authors:}

Oti, Akponanabofa Henry; Farrell, Peter; Abanda, F.H.; McMahon, Paul; Mahamadu, Abdul-Majeed; Mzyece, Dingayo; Akintola, Adeyemi Ayodele and Prinja, Nawal

\section{Abstract}

Purpose: The relative low capital cost and contributions to mitigating global warming have favoured the continuous construction and operation of nuclear power plants across the world. One critical phase in the operation of nuclear plants for ensuring safety and security of radioactive products and by-products is decommissioning. With the advent of digital twinning in the building information modelling (BIM) methodology, efficiency and safety can be improved from context-focus access to regulations pertaining demolition of structures, and cleaning-up of radioactivity inherent in nuclear stations. A BIM-driven framework to achieve a more regulation-aware and safer decommissioning of nuclear plants is proposed. 
Design: The framework considers task requirements, and landscape and environmental factors in modelling demolition scenarios that characterise decommissioning processes. The framework integrates decommissioning rules/regulations in a BIM linked non-structured query system to model items and decommissioning tasks, which are implemented based on context-focused retrieval of decommissioning rules and regulations. The concept's efficacy is demonstrated using example cases of digitalised nuclear power plants.

Findings: This approach contributes to enhancing improvements in nuclear plant decommissioning with potential for appropriate activity sequencing, risk reduction, and ensuring safety.

Originality: A BIM-driven framework hinged on querying non-structured databases to provide context-focused access to nuclear rules and regulations, and to aiding decommissioning, is new.

Keywords: decommissioning, nuclear power plants, BIM, tasks, regulations, context-focussed 


\section{Introduction}

There are currently 31 countries where nuclear plants are being used to generate electricity (IAEA, 2018). Nuclear power contributes a significant share of the electricity mix in countries such as France, UK, Slovakia, Ukraine, Belgium and Hungary. As a result of reliable and efficient outputs, many of these countries are planning on increasing the capacity and efficiency of their nuclear power generation infrastructure in the near future (Pioro and Duffey, 2015; WNA, 2019). For instance, in the UK where nuclear power accounts for over $20 \%$ of the country's electricity (BEIS, 2018), the government and the nuclear energy sector are collaborating in the new Nuclear Sector Deal. In this deal, targets are to achieve: $30 \%$ cost reduction in new build projects, $20 \%$ cost savings in decommissioning and up to $f 2$ bn domestic and international contract wins by 2030 . The deal looks to establish novel ways of developing key, high-value nuclear components, systems and processes. This encompasses aspects of modular and advanced manufacturing /construction, digital engineering execution and assurance over the life cycle of projects to reduce associated costs. Such improvement and expansion are underway, partly because some nuclear facilities have already reached or are approaching their end-of-life and new ones will need to be built. Hence, a review of nuclear power plant (NPP) decommissioning processes to take advantage of contemporary modelling tools such as building information modelling (BIM) and learning from best practice approaches is expedient. Also, currently operating plants with distant end-of-life and those planned for the future can benefit from new innovations.

Nuclear power plants arguably remain one of the most reliable, cheapest and environmental friendly sources of energy in the electrical energy mix available to a number of countries (Brook et al., 2014). One of the major challenges in exploiting nuclear power has been the safe management of radioactive substances during operation and during decommissioning at end-of-life. The decommissioning stage of nuclear facilities is even more critical as it inevitably entails, in addition to 
demolition of structures, handling radioactive materials for safe disposal or neutralisation. Also, decommissioning activities will usually involve professionals/workers from other disciplines such as construction, who may rarely work with radioactive materials in their normal working routines. Decommissioning entails the progressive demolition of buildings and removal of radioactive material. It is hazardous, expensive, time-intensive, and presents environmental risks that must be addressed to ensure radioactive materials are either transported elsewhere for storage or stored onsite in a safe manner (Cumo, 2002, Suh et al., 2018; Patterson et al., 2016). A system that virtually simulates the process is therefore important to mitigate these potential challenges and associated risks. Intelligent digitalisation of information, processes, objects with link to existing policies/regulations that could support work of diverse stakeholders is lacking. Therefore, this research focuses on enhancing safety and smooth execution of NPP decommissioning processes through BIM-driven stakeholder-engagement, guided by context-based access to rules and regulations, including consideration of dismantling sequences and demolition operations.

The innovation of this research is the systematic integration of rules and regulations in a BIM-based framework for decommissioning processes of nuclear power plants. The framework utilises a nonstructured query system to model items and decommissioning tasks, which can be retrieved by means context-focused association to decommissioning rules and regulations. This solution responds to challenges placed on the nuclear industry to reduce capital costs and achieve safer decommission processes and handling of radioactive products and by-products. With the advent of digital twinning in the BIM methodology (Patterson et al., 2016), efficiency and safety can be improved from context-focus access, to regulations pertaining to demolition of structures and cleaning-up radioactivity inherent in nuclear stations. Using BIM, the object-based intelligent parametric modelling of data over the lifecycle of projects, can capture geometric information, attributes of elements and rules governing their use to integrate multi-dimensional $(n D)$ subjects 
(sustainability, health and safety, fire etc.). It presents the construction industry with opportunities to include multidisciplinary information as part of a federated project model (IIhan and Yaman, 2016). BIM can be used to virtually simulate and analyse performance parameters of projects before execution to ensure accuracy, eliminate clashes and reduce errors (Vernikos, 2012; Abanda et al., 2017). In line with suggestions by Ferrada et al. (2014), BIM is one of the vital technological advancement that has been used, in recent times, to explore the integration of $\mathrm{nD}$ modelling aspect of lessons learned and knowledge management on construction projects (Oti et al., 2018). BIM is also useful in providing the opportunity for the preservation of nuclear data in digital environments on a long-term basis, including compactness in archiving for future use (Patterson et al., 2016). Therefore, this research proposes a BIM-driven framework aimed at achieving a more regulationaware and safer decommissioning of nuclear plants. The accompanying objectives are to (i) establish the need for integrating nuclear power plants decommissioning rules/regulations in BIM; (ii) develop and implement a framework for a context-focused query system that links decommission rules/regulations and model items/tasks; and (iii) demonstrate an example case of a digitalised nuclear power plant. Findings from the implementation of the BIM-driven framework suggests achievable improvements in nuclear plant decommissioning pertaining to areas of appropriate activity sequencing, risk reduction and safe material handling.

The remainder of this paper is divided into five sections. Previous and related works are examined in Section 2. Section 3 sets the scene for presenting the approach used in this research work. Section 4 covers the suggested BIM-based framework including a demonstration. A discussion about the implication of the work is summarised in Section 5 followed by the Conclusion in Section 6 . 


\section{Previous/related works}

One target of decommissioning of nuclear plants is to return sites to "greenfield status", and to become relatively certain of their safety status. Once a facility has been successfully decommissioned, it is expected that radioactive danger no longer persists, and it can be released from regulatory processes. This section discusses existing works on decommissioning processes; their regulation and the extent to which they have been digitised to make a case for contemporary BIM applications.

\subsection{Decommissioning processes}

The phases in the life cycle of a nuclear power plant project are siting (location arrangements), design, construction, commissioning, operation and decommissioning as typically delineated in a licensing process (Jeong et al., 2016). Like the earlier phases of the lifecycle of a NPP, activities in the decommissioning phase are relatively well-defined. This can be seen in the Greifswald project (Bond et al., 2004), where decommissioning activities broadly included: (i) post-operational (operation of all systems relevant to storage, removal, inactive system dismantling and decontamination), (ii) dismantling (contaminated and potentially contaminated systems), and (iii) site restoration (dismantling, decontamination and demolition of remaining systems/structures and site restoration/adaptation). The definitions of these phases and constituent activities and strategies for decommissioning may vary from one region, authority or project to another depending on legal, technical, economic and radiological considerations (Cumo, 2002; Suh et al., 2018). In the UK, a vital activity that should precede the technical decommissioning works is the Environmental Impact Assessment (EIA) which includes a specified period (not less than 30 days) of public consultation (Bond et al., 2004). In 1999, it was stipulated that for decommissioning of a NPP to proceed, there must be a consent statement from the Health and Safety Executive which requires the consideration of an Environmental Impact Assessment (EIA) completed by a competent environmental authority 
and an Environmental Impact Statement (EIS) provided by the developer (EC Council Directive, 1985; HSE, 2007). The EIS is expected to specify the option or options combination of decommissioning methods to be implemented. The 1988 decommissioning rule (53 FR 24019) differentiated between acceptable methods. These are: (a) DECON (decontaminate) - the removal or decontamination of equipment, structures, and portions of the facility and site containing radioactive contaminants; (b) SAFSTOR (safe storage) - placing and maintaining the facility in a safe stable state until it is decontaminated and dismantled to levels permitted for licence termination; and (c) ENTOMB (entombment) - the structural encasing of all radioactive structures, systems and components in a time-proof material such as concrete.

Irrespective of the adopted method and in line with specifications in the Code of Federal Regulations (CFR) of United States of America (USA), common activities that support decommissioning (10 CFR 50.2) include decommissioning planning, post-operation, characterisation, decontamination, dismantling and safe storage (Cumo, 2002). A typical sequence of these activities and their relationship is mapped in Figure 1 which closely aligns with what is applicable in the UK (NDA, 2019) and countries such as Sweden (Larsson et al., 2013). The process involves (1) planning for the decommissioning process while the plant is still operating and entails some iterative decisionmaking processes concerning approaches, resources to be deployed, cost evaluations of activities, and the appropriateness of timelines; the early phases of decommissioning plans are essentially made up of the post-operation, (2) planning activities covering works needed to maintain safety until the plant has been shut down; this sets the scene for characterization, (3) defining and categorizing systems, components, structures and processes into a radioactive inventories which then helps to guide decontamination (4) interrogating floors, walls, pipes et al; and certifying decontamination is satisfactory, (5) dismantling according to prescribed methods and approaches for various components, and (6) finally safe storage with defined pre-determined timelines sufficient for the plant to be left dormant and allow adequate radioactive decay under controlled conditions. 
Decommissioning is completed with termination of the nuclear licence. Decommissioning processes have high potential for occupational hazards and are cost and time-intensive with risks of environmental pollution. These issues make it expedient to address the efficient and safe management of the disposal radioactive materials. Recent best practice approaches of design for deconstruction (DfD) which entails allowing for considering safe dismantling of structures from the stage of design, have been suggested in nuclear decommissioning (Akbarnezhad et al., 2014). Many early nuclear plants were constructed before the advent of BIM making their deconstruction to be largely based on manuals (Volk et al., 2019) and therefore highly cumbersome and risky. Therefore, contemporary virtual simulation of decommissioning processes is important to mitigate these potential challenges and risks; this study contributes to addressing that need.

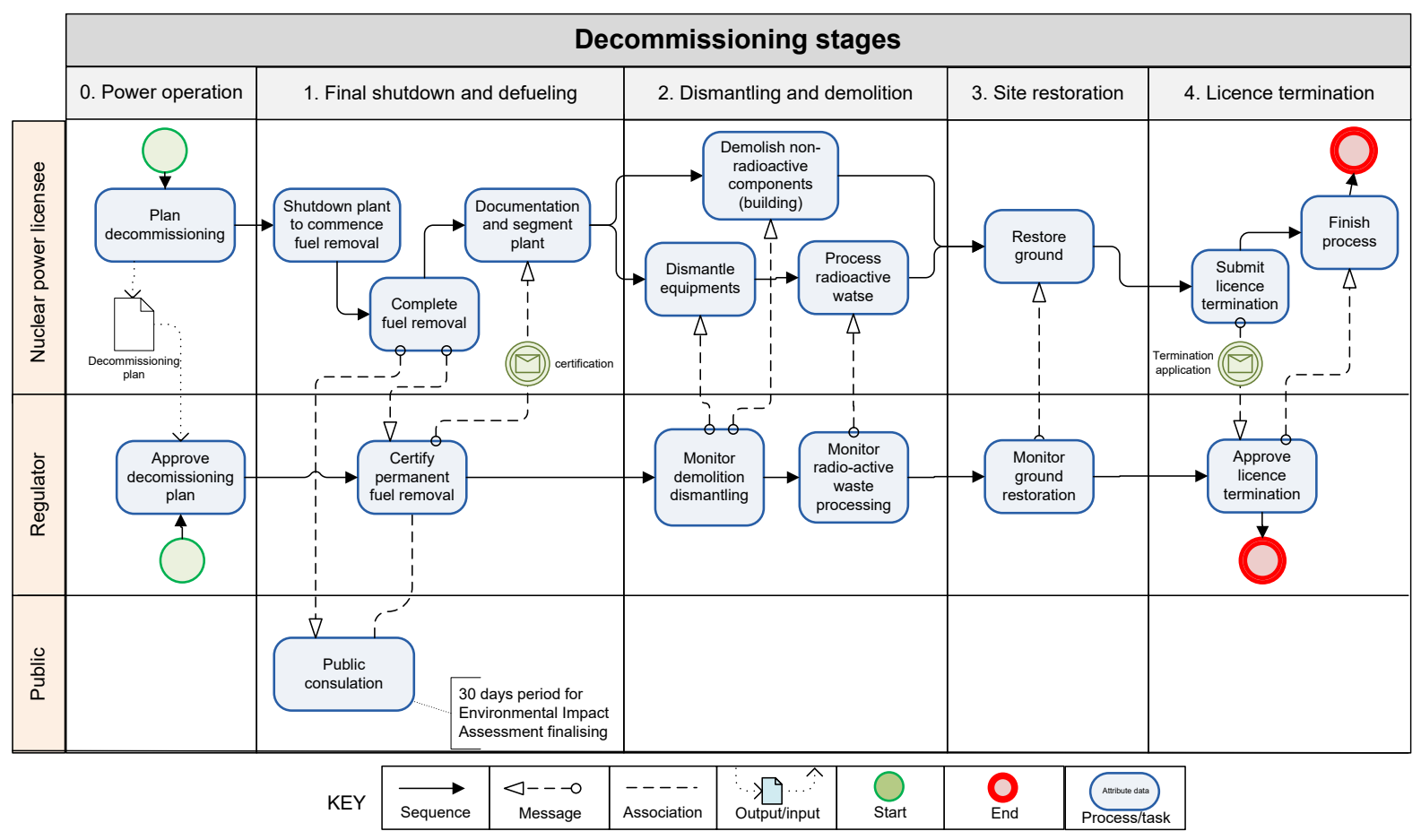

Figure 1: Sequence activities in nuclear power plant decommissioning 


\subsection{Requirements and regulatory controls for decommissioning}

The nuclear power industry is highly regulated at both international and national levels because of its hazardous nature and security risks. An understanding of regulations and their functions is necessary in developing a BIM-driven framework for decommissioning. The world regulatory body, the International Atomic Energy Agency (IAEA) with headquarters in Vienna, is authorised by statute "to establish standards of safety" and "to provide for the application of these standards". The IAEA effort is aimed at creating multilateral, legally binding agreements important for enhancing nuclear, radiation and waste safety around the world by means of international conventions. Consenting countries are bound by these conventions as legal instruments. Countries that have signed and ratified the legal and regulatory frameworks of NPPs designed by the IAEA may develop further regulations and guides tailored to or aligned with national policies through national regulatory bodies. The responsibilities of regulatory bodies vary and may cover the IAEA defined areas of regulatory guidance; licensing and licensing documents; assessment of safety; regulatory inspection and enforcement; regulatory competence and quality of work; emergency preparedness and public communication. Safety through prevention has always been an important concern in the history of nuclear power development and it remains a key defining factor for future developments (IAEA, 2018). Consequently, the IAEA initially established over 200 safety standards under the series of (i) Nuclear Safety Standards (NUSS); (ii) International Basic Safety Standards for Protection Against Ionising Radiation and for Safety of Radiation Sources (the Basic Safety Standards), with supporting documents; (iii) Radioactive Waste Safety Standards (RADWASS); and (iv) Regulations for the Safe Transport of Radioactive Material. In 1996, these were coalesced into two: Safety Standards (spell out objectives, concepts, principles, requirements and guidance) and Safety Reports Series. The Safety Standards is comprised of 3 parts: Safety Fundamentals, Safety Requirements and Safety Guides. Safety Fundamentals are essentially the IAEA Safety Standards series policy documents. The Safety Requirements are conditions (with 'shall' statements) that must be met in order to ensure the 
safety of a particular activities, while Safety Guides are recommendations, usually with "should" statements, to ensure that safety requirements are met.

Until the Fukushima nuclear accident in March 2011, nuclear policies did not put much emphasis on the magnitude of safety hazards that can be abruptly induced by the effects of natural occurrences (Kim et al., 2013). NPP licensees had concentrated mainly on demonstrating compliance with modern standards for 'design basis' events (DECC, 2013). A swift response to this natural disaster called for the review of another dimension of safety in nuclear power facilities with respect to triggering events such as earthquakes and flooding. For example, on the $25^{\text {th }}$ of March 2011, the European Commission declared the need for a comprehensive safety review and transparent risk assessment 'stress test' for all EU nuclear plants (ENSREG, 2011). Consequently, the European Nuclear Safety Regulators (ENSREG, 2011) defined 'stress tests' as targeted assessment of safety margins in extreme natural events. The tests consist of (i) an evaluation of response of nuclear plants to extreme conditions and (ii) the verification of plausible measures for the prevention and mitigation-based defence-in-depth logic (initiating events, consequential loss of safety functions and severe accident management). Although, some reports (TEPC, 2011; DECC, 2013) have emanated from the assessment of the Fukushima disaster as well as modifications of safety policies (ENSREG, 2011), literature of how to digitise and model information and processes to actualise a comprehensive safety and transparent risk assessment aligned with the contemporary digital technology affordance is still developing. This research proposes contributing to closing this gap with a focus on the area of context-focus access and utilisation of decommissioning rules and regulations.

\subsection{Digital transformation and BIM in nuclear decommissioning}

In simple terms, digital transformation may be referred to as "going paperless" (Patel and McCarthy, 2000). This can result from adoption of new technologies and can affect the overall structure of businesses. Aspects of business that could be affected range from the generation of information, 
keeping of records, and the exchange and use of data to execute vital processes that define business functions. It can have varying perspectives and degrees of thoroughness depending on goals (Matt et al., 2015). Digital transformation can transcend automation and optimisation, changes in process paradigms, implications for product and service improvements, and redefinitions of business models. One of the early cases of digital transformation of decommissioning identified in the literature is that of a Japanese Power Demonstration Reactor (JPDR) initially developed for UNIX and then extended to the Windows Operating System (Yanagihara, 1993; Yanagihara et al., 2001). It was termed COSMARD (Code System for Management of JPDR Decommissioning) and makes use of treestructured data processing algorithms reflecting the Work Breakdown Structure (WBS) of typical decommissioning processes including manpower needs of both manual and remote dismantling tasks. The system applies developed mathematical formulas and generated unit factors of work items to evaluate decommissioning project management data for enhancing the forecasting of manpower needs and costs. The challenge with COSMARD is that it uses project-specific data which requires lots of effort to develop. Also, it is difficult to apply on other projects due to inherent variations across different decommissioning scenarios, project locations and characteristics. Another early example of interest is the DEXUS (Decommissioning Engineering Support System) used in Japan to support the termination of the Fugen Nuclear Power Station (Iguchi et al., 2004). The DEXUS, built on the COSMARD project, combined 3-dimensional (3D) Computer-Aided Design (CAD) and Virtual Reality (VR) to optimize project workload, exposure dose, waste mass and cost by selecting appropriate dismantling procedures at the planning stage of decommissioning. The goal was to contribute to reducing decommissioning costs and further improve overall safety. In the context of nuclear plants that have been (or are near) shutdown in Taiwan, the object-oriented Integrated Decommissioning Information Management Systems (IDIMS) was developed to keep comprehensive records of all activity data generated from the processes of planning, licensing, post-operation radioactive waste management and storage (Chou and Fan, 2006). 
Although there are more recent works on digital transformation in nuclear power plants, they have concentrated on specific components or specialised aspects. For example, the Consortium for Advanced Simulations of Light Water Reactors (CASL) in the USA developed a predictive simulation environment to tackle leakage of fuel rods in pressurized water reactors caused by wear and tear of the Gird-to-Rod Fretting (GTR) (Lu et al., 2011). Another notable example is the investigation to handle remote maintenance of diverters in fusion advance studies of torus (FAST). FAST, based in Finland (Tampere), acts as a satellite tokomak that provides an interactive review platform through virtual prototyping techniques to actors in a project (Di Gironimo et al., 2014). The system's uniqueness is that it can create maintenance iterations including the analysis of current solutions and the proposal of new options based on established requirements and identified improvements to reach shared optimised solutions. Finally, the work of Patterson et al (2016) on proposing a framework for an integrated nuclear digital environment (INDE) is of interest. Building on their earlier work (Patterson et al., 2013), the action of monitoring strain fields between a prototype and its manufactured equivalent was compared to the principle of developing digital twins to proposed INDE. The framework map flows from aspects of prototyping, construction, operation, shutdown and the decommissioning of nuclear plants in real-world scenarios to their corresponding digital environment which could result in added values from potential exemplar applications. Patterson et al (2016) argued it is time a digital nuclear environment/twin is developed to support the design and operation of nuclear facilities. This will help to harness the benefits of altering the requirements of creating expensive physical mock-ups and tests, increase returns on investment through more efficient operation, reduce decommissioning costs and improve public awareness and participation. Although comprehensive, a vital aspect of implementation is lacking in the presentation of INDE, which is essentially a high-level framework. As such, this proposed research extends a similar framework hinged on BIM-enabled application to the aspect of implementation and focuses on decommissioning to allow proposed information modelling process to drill down to activities. Thus, with the internationalisation of information management approaches in construction, BIM is poised 
to become the widely used standard, for structured repositories for assets (new and existing) and project information in making whole life cycle decisions around planning, design and construction (BSI, 2019).

\subsection{Summary of research gaps}

The first objective of this research, to establish the need for integrating nuclear decommissioning rules/regulations in BIM, is accomplished by a review of the literature, culminating in identification of research gaps developed from discussions of previous works. A major challenge in the use of nuclear power plants for the generation electrical energy, is the safe management of radioactive substances during operation and at end-of-life. Nuclear decommissioning processes at the end-oflife, are governed by rules/regulations at both national and international levels. While decommissioning may involve intense planning, typical activities encompass systematic dismantling of components, demolition of structures and removal of radioactive material. Such activities will involve professionals from other fields such as construction who do not constantly work with radioactive materials in their conventional practices and job routines. Stakeholders in this category will need to be quickly become abreast with huge databases of information on decommissioning rules and regulations which is difficult without the aid of contemporary digital transformation applications. Such integration of decommissioning rules and regulation for context-focus access by stakeholders does not currently exist and is therefore the focus of this study.

Although recent DfD approaches are advocated, the decommissioning of early nuclear plants constructed before the era of contemporary digital transformation are hinged on manuals (Akbarnezhad et al., 2014a; Volk et al., 2019). Some studies have considered the possibilities for digital applications using BIM (Cheng and Ma, 2013; Akbarnezhad et al., 2014a), albeit, mostly concepts that require some years to be verified in real-life projects. This is because many new projects delivered using BIM applications are yet to reach their end-of-life to activate intended 
deconstruction from associated DfD specifications. The only option, therefore, for any real-life demonstration of digitalisation concepts is to capture as-built information of projects due for deconstruction and integration into contemporary BIM software packages by using point clouds as suggested in Akbarnezhad et al (2014b), Hubner et al (2016) and Volk et al (2019). The concept proposed by Volk et al (2019) suggested added advantages of quantifying project time, materials and costs ranges associated with decommissioning, but the aspect of readily accessing regulations to guide targeted decommissioning activities is a gap not specifically covered. Keeping abreast with context-focused regulatory information in decommissioning planning and execution is vital, which is an area of focus of our research. The method employed in accomplishing the implementation is discussed next.

\section{Method and implementation}

This work further demonstrates suggestions that BIM can be expanded to incorporate various $n$ dimensional information modelling aspects of different scales and types of projects (Oti et al., 2018) including the decommissioning of NPP. The challenge is that the level of intelligent digitialisation of information, processes, objects and links to existing policies/regulations in the to make immediate sense to stakeholders is still developing. Herein lies a key area of focus of this research; to enhance safety and smooth execution of NPP decommissioning processes through BIM-driven stakeholderengagement with guiding rules and regulations including the sequences of dismantling and demolition operations. As illustrated in Figure 2, the research is approached conventionally through the review of the literature, rules, guides and regulations around the development of NPP to establish gaps as presented in Section 2. Outputs from the literature review count towards fulfilling the first research objective of establishing the need for integrating nuclear decommissioning rules/regulations in BIM. The development and implementation of a framework for the contextfocused querying linking decommission rules/regulations and model components/tasks, associated with the second objective, is fulfilled in this Method section. Also, a demonstration of the efficacy of 
the concept using two example cases of a digitalised nuclear power plant in line with the third objective is presented in Section 4. This preliminary aspect of the research also explores approaches to digitising components of a typical NPP and modalities, to capture dismantling/demolition events in a BIM environment. The convenient option was to combine Autodesk Revit and Navisworks for design and project management functionalities respectively. An essential aspect of the digitisation process is to gather adequate knowledge of how the elements in the developed model are aggregated. This informed how new attributes were created or added to the model items to align with conventional component nomenclature in NPPs. Also, the modification of model item attributes, dictates the information mapping to be carried out in spreadsheets and subsequent referencing in a modelling and programming environment.

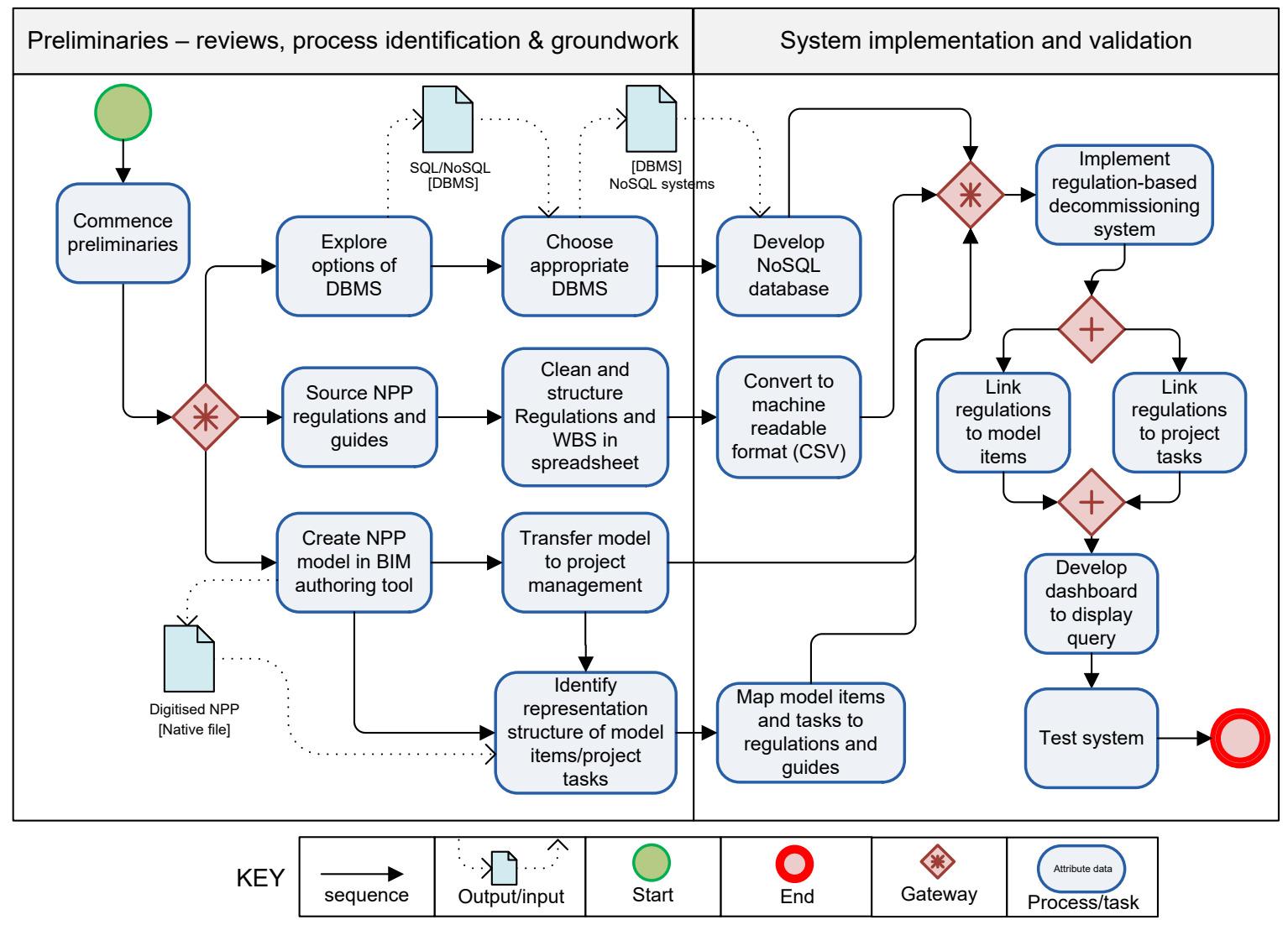

Figure 2: Research activity flowchart 
The second aspect of the research involved implementing the proposed system in a .Net Framework environment, including the testing of the system. The elements required to progress with this stage of the implementation include a combination of information on model items, regulations and decommissioning tasks obtained from the model, comma-delimited file and database management system. Information is extracted and transformed into objects and functions in C\# programming environment linked to BIM-enable tool (Navisworks) through an Application Programming Interface. The approach for information modelling in this research work aligns with the Rapid Application Development (RAD) principle (Maner 1997). A simplified representation of the overall system showing the input and output is expressed by IDEFO (Icam (Integrated Computer-Aided Manufacturing) DEFinition for Function Modelling 0) as shown in Figure 3. The input is the digitised NPP which is combined with the ingredients to yield the output of digitised decommissioned processes. Further, Business Management Process Model and Notation (BPNM) is employed to capture the relationships and interactions of various components of the system in a compact way (Tangkawarow and Waworuntu, 2016). 


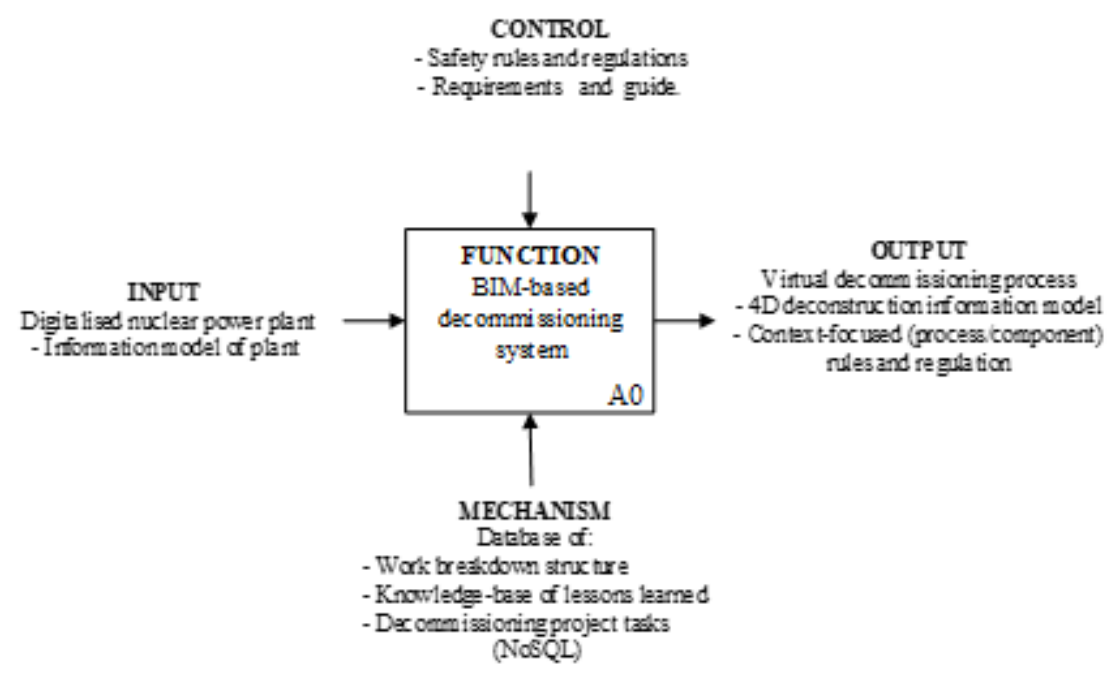

(a)

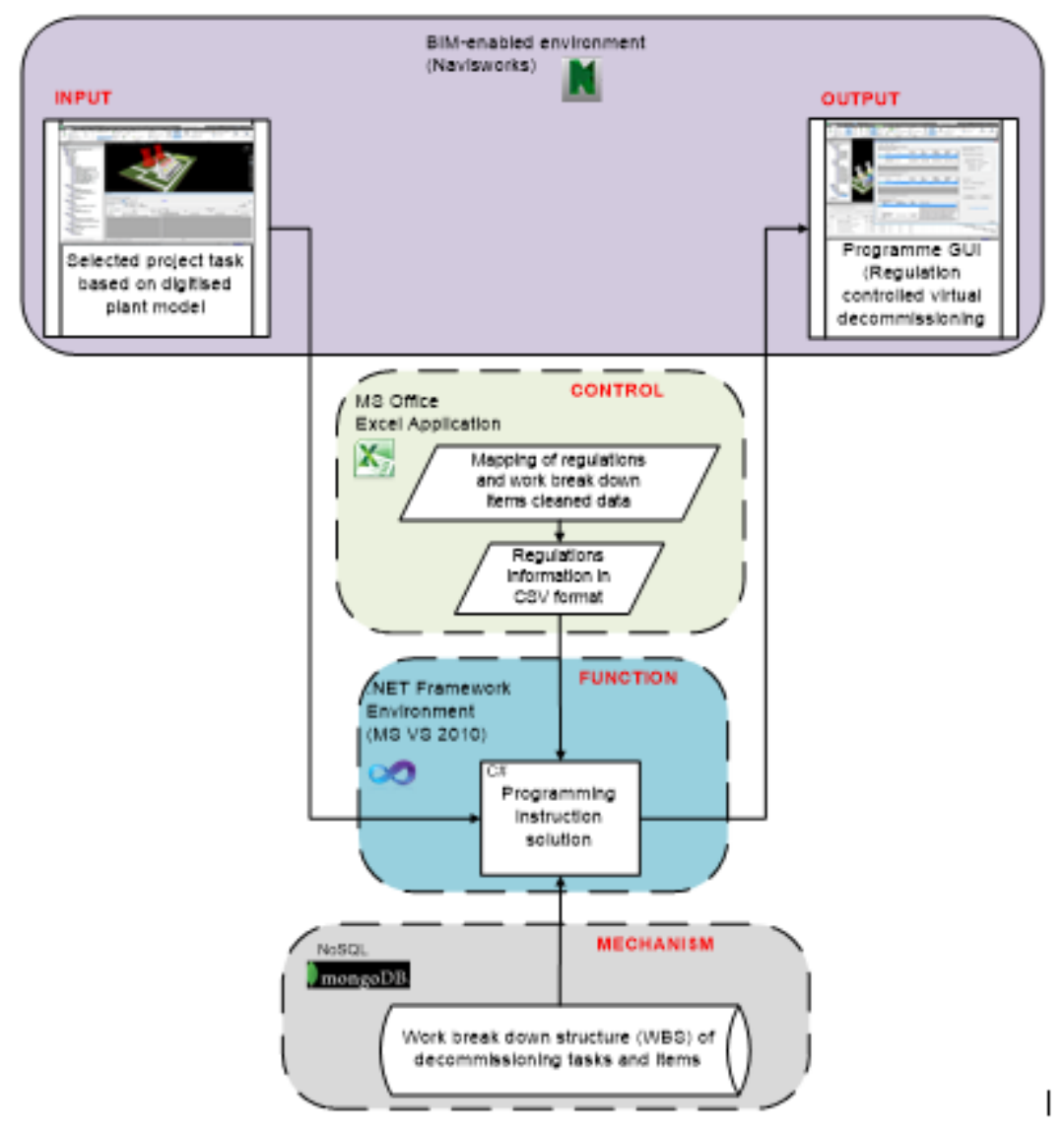

(b)

Figure 3: (a) Proposed BIM-based framework and (b) Components of nuclear plant decommissioning systems 


\subsection{A BIM-based decommissioning framework}

The proposed BIM-based decommissioning framework is categorised into components as shown in Figure 3 and discussed to a greater depth in this section. Also discussed here, is how components were combined to implement the system and a guide to its operation. Aspects relating to testing the system are presented in the subsequent section.

\subsubsection{Components of the BIM-based decommissioning framework}

Based on the IDEF diagram (Figure 3), the framework comprises five modules: Input, Control, Mechanism, Function and Output. The Input consists of the digitised model of the NPP, the Control encompasses all the regulatory instruments that moderate the functioning of the industry while the Mechanism consists of representations of information that enhance the structured mapping and use of components/elements associated with the digitised model. The Function represents the rulebased digitisation environment for harnessing the combination and permutation of resources to yield the Proposed Output of an integrated virtual decommissioned process/model. Discussions under this section dwell more on modules that flow into the Function; the Function and Output are presented in detail in Section 4.

\subsubsection{Digitisation process of Nuclear Power Plant (Input)}

Nuclear power plants are specialized structures requiring more stringent guidelines in designing and constructing the various component parts than conventional structures such as housing and factories. A typical nuclear plant for power generation and transmission consists of a: containment building housing two steam generators, a uranium fuel tank (reactor vessel) and connection pipes; turbine plant which is continuously cooled by water; generator powered by the turbine; transformer for moderating the transmission voltages from the generator; a cooling tower that provides and 
control the temperature of water used for cooling the turbine; water tank/body from where the cooling tank obtains water for cooling the turbine; electricity transmission towers/cables and administrative building units. The Input for the developed system requires project management functionalities, such as 4D, embedded in BIM. Since most BIM authoring design tools are not equipped with 4D functionalities and vice versa, the digitisation of the Input (NPP components) for the developed system is carried out in two phases to take advantage of the varying strengths of existing BIM authoring tools. The first phase entails the modelling of the various components of NPP in a BIM authoring tool, such as the Revit Building Design Suite, at a level of development (LoD) that will allow adequate demonstration of the research concept (discussed in Section 5). The Revit Building Design suite is one of the leading building information modelling software packages used by architects, structural engineers, mechanical, electrical, and plumbing (MEP) engineers to design structures and systems (Abanda et al., 2015). The software is equipped with utilities that allows object-based parametric designs in 2-dimension and 3-dimensions connected to rich databases of component information. In the second phase, the developed model is then transferred to a project management tool for further analysis. In this phase, the model is loaded in Navisworks Manage, with vast project management capabilities, and serves as the environment for developing the proposed system.

\subsubsection{Safety rules, requirements and guides (Control)}

The main aim of regulations, rules, and guides as published by national and international regulatory bodies for decommissioning and indeed other stages of the NPP life cycle, is to ensure that safety requirements are met throughout the processes in question; decommissioning in this case. As such, relevant actions encompass reviewing decommissioning/license termination plans, conducting targeted inspections and monitoring constituent activities to keep abreast with status regarding reductions and stabilization of radioactive contamination. This requires that regulatory bodies and 
licensee organisations, including their personnel directly involved, must be conversant with rules and guidelines. Rules and guidelines governing NPP are vast and detailed, which are challenging to digest without supporting systems such as that proposed in this research. For illustration purposes the rules captured as part of Control covers Maintenance Rules, Maintenance of Final Safety Analysis Reports, Fire Safety Requirements and Actions by Certified Fuel Handlers as discussed in USNR Regulatory Guide 1.184 (USNRC, 2000). The information in the regulations and guides are transferred to spreadsheets and mapped to relevant work breakdown items to align with bill of items for decommissioning works as will be executed on-site.

\subsubsection{Database of WBS and Regulations (Mechanism)}

The mechanism of the developed system consists of NPP regulations and guides which have been mapped to work breakdown structure of decommissioning tasks stored in a NoSQL database. NoSQL databases have been specially chosen for this work because of their ease of manipulation once required links are established. Information entries are stored as documents in databases for which IDs (MongoID) are generated automatically, which helps to facilitate query processes.

\subsection{Implementation and operation of the framework}

The Input, Control and Mechanism components are pulled together in a system (Function) developed in a C\# programming environment under the .NET Frameworks. This implementation takes advantage of the interoperable capabilities .NET Frameworks has with BIM tools such as Revit and Navisworks as well as the NoSQL database managements systems, MongoDB. It is vital that a link to the local Host of MongoDB, where Control information is domiciled, is established from the on-set, to allow interaction from the Function. This connection is created through MS-DOS command line based on prior installations. Accordingly, associated MongoDB drivers are installed in C\# via 
NuGet Package Manager to facilitate the connection. This connection must be in place to allow regressive testing of the implementation as work progresses in the Navisworks environment linked to $\mathrm{C \#}$ through the Application Programming Interface (API). The API is wrapped around three frequently used assemblies; the Autodesk.Navisworks.Api.dll, Autodesk.Navisworks.Automation.dll and Autodesk.Navisworks.API.Controls.dll. The first is used for establishing links to Plug-ins or to work with the Controls API; the second is for Automation to drive Navisworks and the GUI Controls or access to Navisworks documents within a third party application library (Autodesk, 2018). In this implementation, the proposed system/tool is embedded into Navisworks Ribbon with a resulting window that can blend into the Navisworks GUI. Taking advantage of the RAD methodology, the system is re-assessed to incorporate further improvements through re-specification and re-design to achieve maturity and desired output.

The matured system is operated in the Navisworks environment which will usually happen during planning and project management activities that concern decommissioning. Figure 4 shows the flow of actions for operating the system. The user commences with opening the NPP model in Navisworks (1) and progresses to call (activate) the decommissioning programme from a link button situated on the Navisworks Ribbon (2). The system responds by loading the proposed programme (3) and entering pre-developed decommissioning work breakdown items or new bespoke programme, where available, in the Navisworks Timeliner (4). The next action is to either enter task items according to the work break down structure for decommissioning or load pre-design task lists from a database that needs to be uploaded first through an adapted plug-in from the Navisworks API development team. The challenge with the latter is that the instantiation of task items when loaded is partial. This inhibits the response to check events and so needs some further development. The checking of a task (5) activates its potential to link with the database when a model item from the NPP component structures is selected (clicked). This action triggers a series of events based on the 
task keyword identified by the system (6). The first two are that the selected model item and the checked decommissioning task are relayed to the database to fetch corresponding regulations and connecting information as further described in Section 5. Consequently, the windows form to display the output is also called (7). As these appear on the screen, the users then need to assess and assimilate the output to assist in the decommissioning processes $(8,9)$ and then to continue $(10)$ or quit the programme (11).

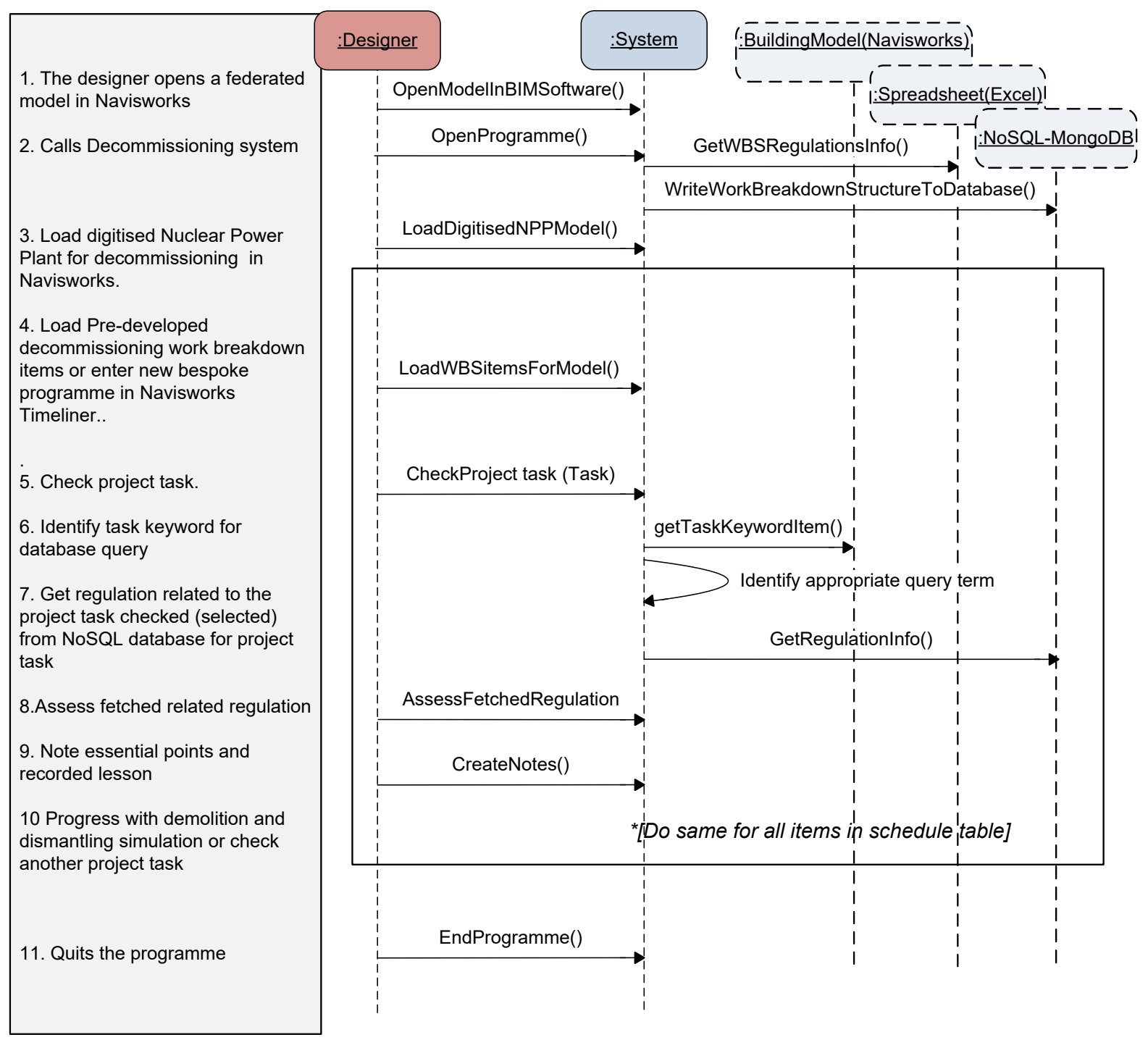

Figure 4: Nuclear power plant decommissioning system operation 


\section{Demonstration of the framework with test cases}

To meet the third research objective, this section presents the proposed framework using two example cases of digitalised nuclear power plants that have been hypothetically modelled in Revit, a BIM-enabled tool.

\subsection{Description of test cases}

The first test case project is a compact model reflecting the typical components of nuclear power plants as discussed in Section 3.1.1. The model, developed in Revit, covers a total site area of 22,565 $\mathrm{m}^{2}$ with approximately $55 \%$ built-up of components of typical nuclear plants, including padded areas and road networks. It is made up of twin cooling towers, both $54 \mathrm{~m}$ high. Other structures include twin containment buildings, a turbine building, a cooling pool and administrative building (see Figure 5(a)). These structures have been modelled at LoD3 but allowing sufficient detail to be transferred to a project management tool, Navisworks, for further analysis. The levels and material components of the structures can be defined in a BIM authoring tool (Revit) which allows for a distinct classification into standard tree items in Navisworks as further described in Section 4.2. As a second test project to demonstrate the efficacy of the research concept, the model of a European Pressurised Reactor (EPR) (AREVA, 2005) was also developed in Revit as shown in Figure 5(b). These models in Figures $5(a)$ and $5(b)$ are intended to show that the research concept can be applied to different models and nuclear regulations of any country. 


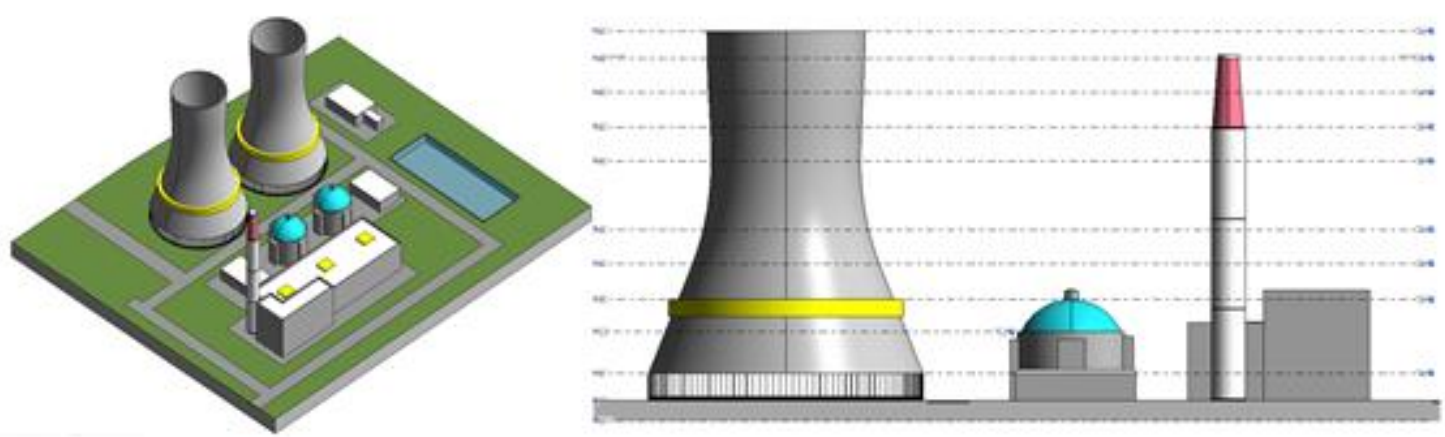

(a)
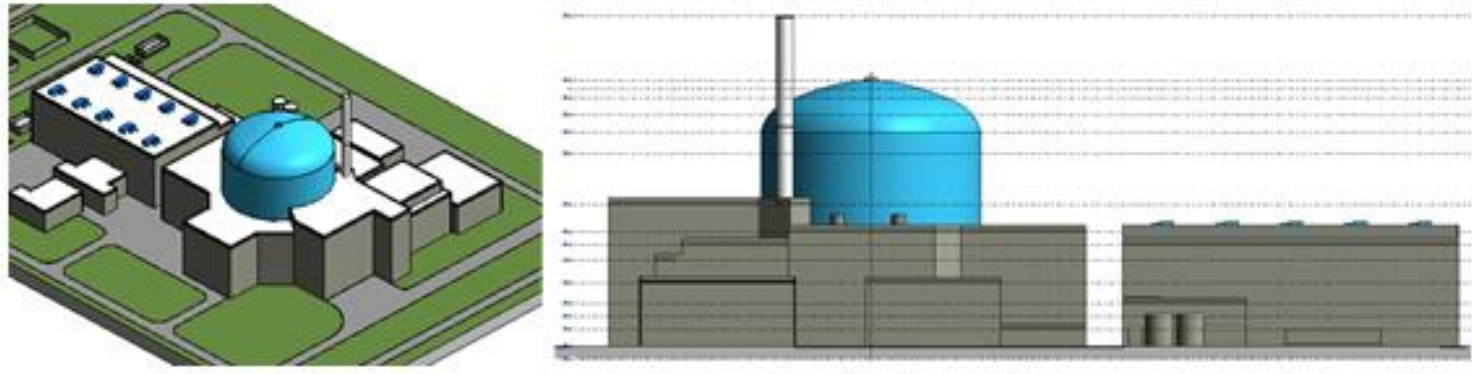

(b)

Figure 5: 3D and Elevation of (a) a PWR Nuclear plant and (b) a UK EPR NPP models

\subsection{System application and outputs}

As automatically defined in Navisworks, the tree items help in developing the project decommissioning task in the programme schedule (Figure 6). The Timeliner shows a typical work programme of decommissioning tasks which is already extant in planning software packages. However, linking such tasks at various granularity to associated decommissioning rules and regulations for context-focused accessibility and use by stakeholders is novel and is the focus of our research. Although the decommissioning tasks have been simplified, the tree items can be associated with corresponding decommissioning tasks which in turn complies with standard specified processes and activities as outlined in Table 1 as defined in the US CFR. The rules indicated 
in Table 1 are high level and can relate to several tasks. For example, the requirement to conduct and continuously update fire safety analysis throughout the decommissioning processes is covered in the Fire Safety Analysis Report. Fire safety is not limited to particular structures, components or processes but affects all structures of the plant and all the tasks carried out during decommissioning. However, it may be more critical for specific tasks that are prone to inflammation such as the handling of spent fuel. This implies that more specific requirements or regulations at a lower level could be associated with decommissioning tasks. In this research, these regulations were identified and mapped to decommissioning tasks and linked via a NoSQL database (MongoDB) to demonstrate this as a proof of concept. Similar selected sections of UK nuclear regulations as specified by the ONR are captured in Table 1 used for demonstration with the NPP model in Figure 6.

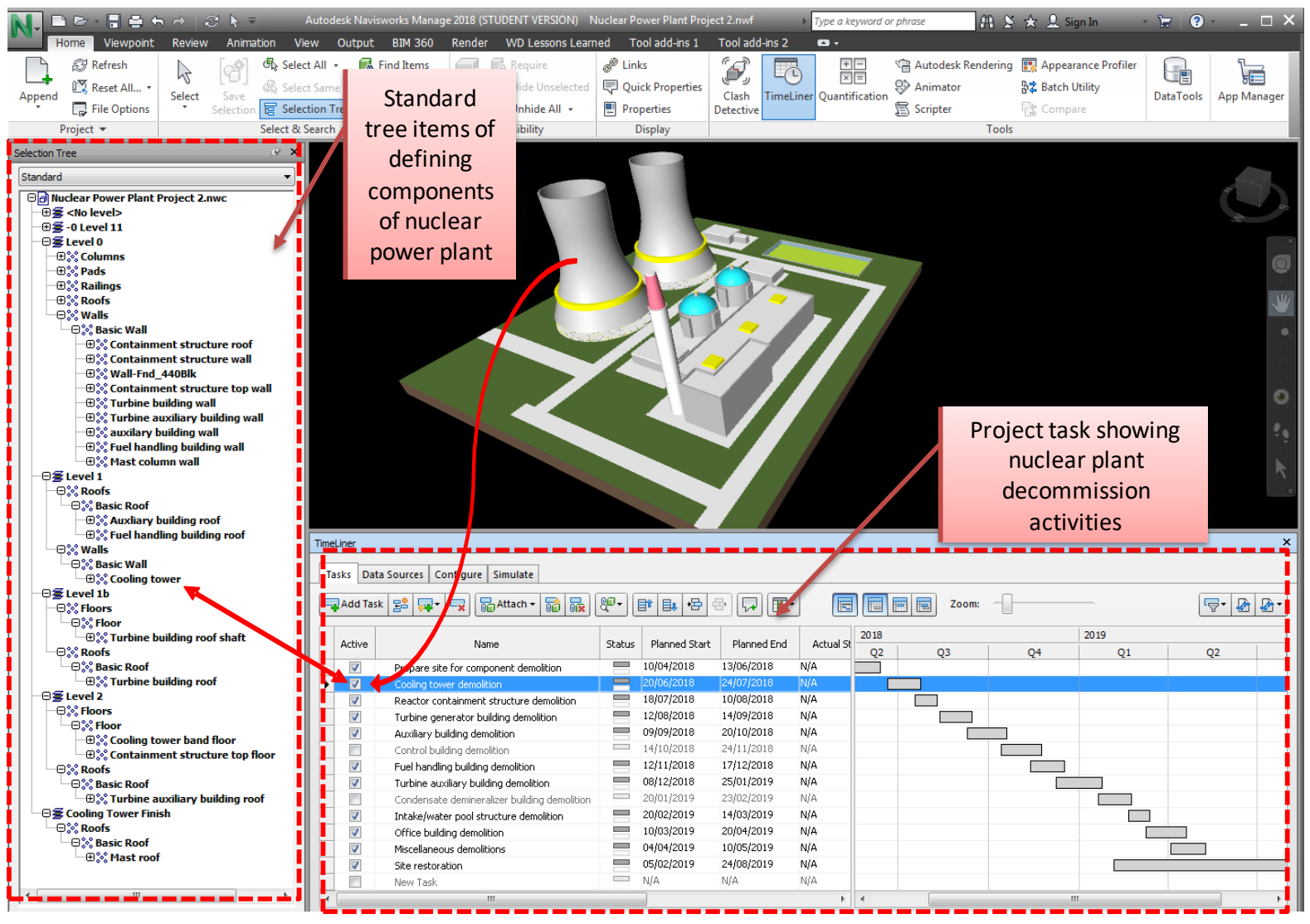

Figure 6: Decommissioning task mapped to components of a PWR Nuclear Plant 
Table 1: Some NPP decommissioning rules and tasks in the USA (USNRC, 2000) and UK (ONR, 2019)

\begin{tabular}{|c|c|c|}
\hline $\begin{array}{l}\text { Rule/requirements } \\
\text { (related clause) }\end{array}$ & Sub-processes and activities & Associated general decommissioning tasks \\
\hline \multicolumn{3}{|l|}{ United states of America } \\
\hline $\begin{array}{l}\text { Maintenance rule } \\
\text { (CFR 50.65(a)(1)) }\end{array}$ & $\begin{array}{l}\text { Monitor performance or condition of structures, systems or components } \\
\text { (SSCs) associated with storage, control and maintenance of spent fuel in safe } \\
\text { condition }\end{array}$ & \multirow{8}{*}{$\begin{array}{l}\text { - Reactor vessel and internals } \\
\text { - Steam generator } \\
\text { - Fuel building decontamination } \\
\text { - Potential radioactive system decontamination and removal } \\
\text { - Component cooling water removal } \\
\text { - Chemical and volume control dismantling and removal } \\
\text { - Containment spray dismantling and removal } \\
\text { - Cleaning of radioactive waste treatment } \\
\text { - Dirty radioactive waste treatment } \\
\text { - Main steam (within containment) cleaning } \\
\text { - Radioactive gaseous waste system cleaning } \\
\text { - Residual heat removal, Safety injection, Spent fuel cooling } \\
\text { - Electrical components and annunciators } \\
\text { - Stainless steel piping }\end{array}$} \\
\hline $\begin{array}{l}\text { Final safety analysis Report } \\
\text { (CFR5 50.59) }\end{array}$ & $\begin{array}{l}\text { Facility description at shut down, radioactive waste management, radiation } \\
\text { protection, procedure for the conduction of operations, Site characteristics } \\
\text { and accident analysis }\end{array}$ & \\
\hline $\begin{array}{l}\text { Fire protection requirements } \\
(10 \text { CFR } 50.48(f)(1))\end{array}$ & $\begin{array}{l}\text { Maintenance and revision of fire protection programmes. Targets include } \\
\text { prevention of fire, rapid detection of fire hazard, minimize risk of fire-induced } \\
\text { radiological hazards }\end{array}$ & \\
\hline $\begin{array}{l}\text { Actions by certified fuel Handlers } \\
(10 \text { CFR } 50.54(y))\end{array}$ & $\begin{array}{l}\text { Permission for reasonable action that deviates from technical specification in } \\
\text { emergency situations. }\end{array}$ & \\
\hline \multicolumn{2}{|l|}{ United Kingdom } & \\
\hline $\begin{array}{l}\text { Maintenance, Testing and } \\
\text { Inspection } \\
\text { (NS-TAST-GD-026 R5 } \\
\text { Section 5.105) }\end{array}$ & $\begin{array}{l}\text { Structures, systems and components (SSCs) should be capable of delivering } \\
\text { their required safety function until the associated hazards have been removed } \\
\text { or mitigated. There should therefore be adequate consideration of continued } \\
\text { maintenance, testing and inspection of SSCs during decommissioning until the } \\
\text { SSC is no longer required, as justified within the safety case. }\end{array}$ & \\
\hline $\begin{array}{l}\text { SAFETY VERIFICATION } \\
\text { Contents, review and update of the } \\
\text { safety case for decommissioning } \\
\text { (NS-TAST-GD-026 R5 } \\
\text { Section 5.131) }\end{array}$ & $\begin{array}{l}\text { Licensees should periodically review the safety case to confirm the } \\
\text { decommissioning activities and states are and will continue to be in } \\
\text { accordance with regulatory expectations and legal requirements. Such } \\
\text { reviews should also identify and evaluate the safety significance of any } \\
\text { deviations from applicable current safety standards and relevant good } \\
\text { practice and ensure an adequate plan to address such deviations are } \\
\text { implemented. }\end{array}$ & \\
\hline $\begin{array}{l}\text { Decommissioning reporting and } \\
\text { Licence termination conditions } \\
\text { (NS-TAST-GD-026 R5 } \\
\text { Section 5.134) }\end{array}$ & $\begin{array}{l}\text { The decommissioning plan and associated programme(s) should include } \\
\text { sufficient short and long-term milestones and deliverables to enable progress } \\
\text { to be monitored. These milestones will usually coincide with major step } \\
\text { changes hazard profile of the site, as associated with the transition from one } \\
\text { stage of decommissioning to the next. The licensee should develop suitable } \\
\text { metrics to facilitate monitoring and reporting against the identified } \\
\text { decommissioning milestones }\end{array}$ & \\
\hline
\end{tabular}


Figures $7(a)$ and (b) show the output of system interactions resulting from calling the NoSQL stored regulations linked to the respective NPP components and decommissioning tasks. Figure 7(a) is associated with PWR and shows nuclear regulations (CFR) from the USA while Figure 7(b) illustrates a similar demonstration with an EPR model and UK nuclear regulations as stipulated by the ONR. These outputs are triggered when a specific decommissioning task of interest is selected, and the user takes a 'walkthrough' the model. In this case, the roof of the turbine building is highlighted from a mouse-click event triggering a corresponding query that outputs the regulations relating to the decommissioning process specific to the turbine building. Similarly, a task associated with the demolition of the cooling tower is selected and the corresponding detailed regulation listed and states thus: "A safety case should be provided to demonstrate the safety of the decommissioning plan and its associated decommissioning activities and then kept up to date as work progresses. For the case of controlled demolition using explosives; ensure the enforcement of exclusion zones around the plant and demolition work is carried out safely and effectively in a controlled and regulated working environment. Ensure remains from controlled demolition such as debris and rubble are cleared and steel reinforcement bars separated from concrete and sent for recycling where applicable. Concrete materials should be crushed and used as infill to restore a level surface to the site where possible". Such regulations can be drilled own to specifics, based on the granularity of specified decommissioning tasks and associated digitised nuclear power model components. 


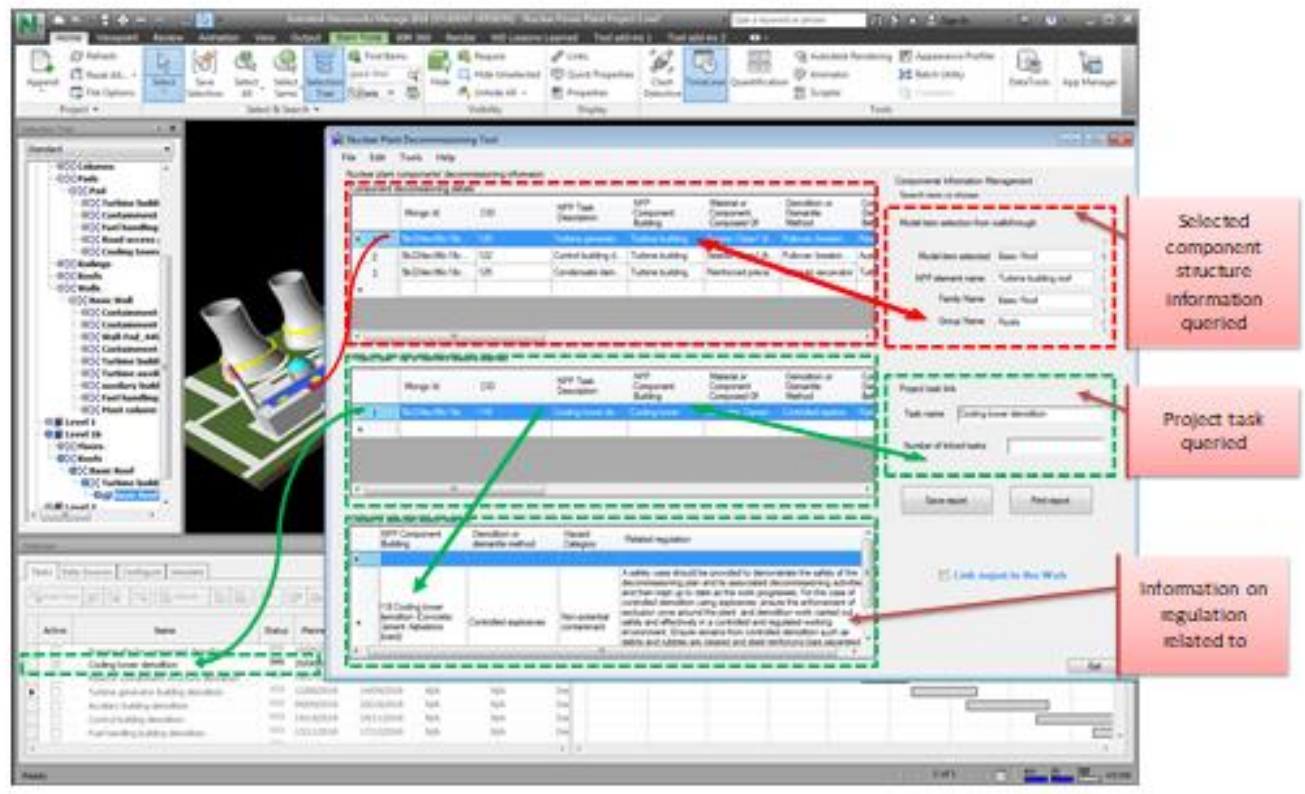

(a)|

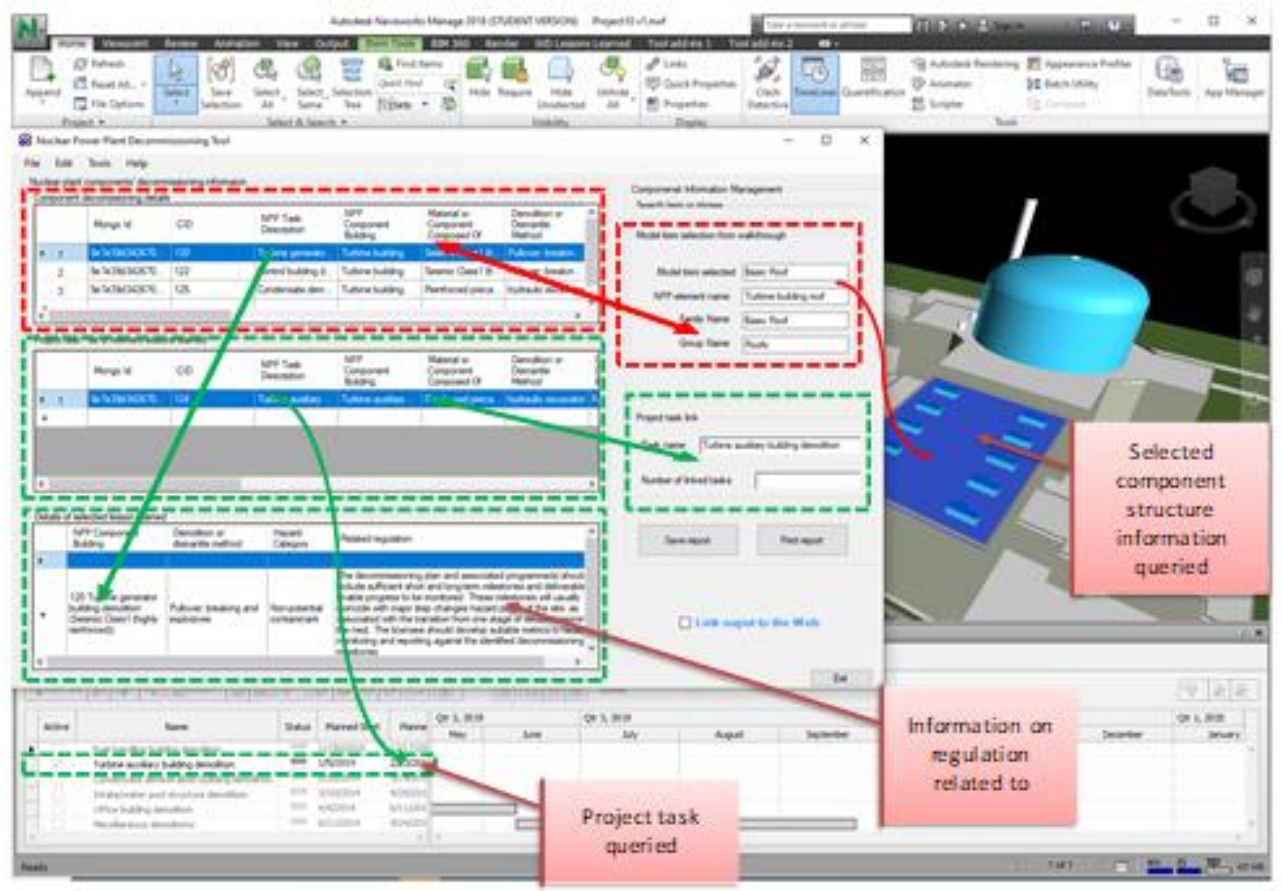

(b)

Figure 7: Query results of component structures and decommissioning task of (a) PWR NPP and (b) EPR NPP. 
Another useful aspect of implementation is simulation of decommissioning processes in accordance with defined tasks. The level of granularity depends on how fine sub-tasks have been defined and attached to corresponding model components or elements. To a large extent this also depends on the level of detail to which the modelling has been carried out in the original modelling environment, such as Revit. In this, simulation the demolition function is utilized in Navisworks to append the NPP model items meant for demolition to the respective decommissioning tasks. The sequence of demolition can be maintained and phases can be delineated by appropriate colour coding as indicated in Figure 8. The sequence of the order of decommissioning activities may vary from project to project as already discussed in Section 2.1. In this case, the controlled demolition of the cooling towers is assumed first and ending up with the communication mast as seen in Figure 8.
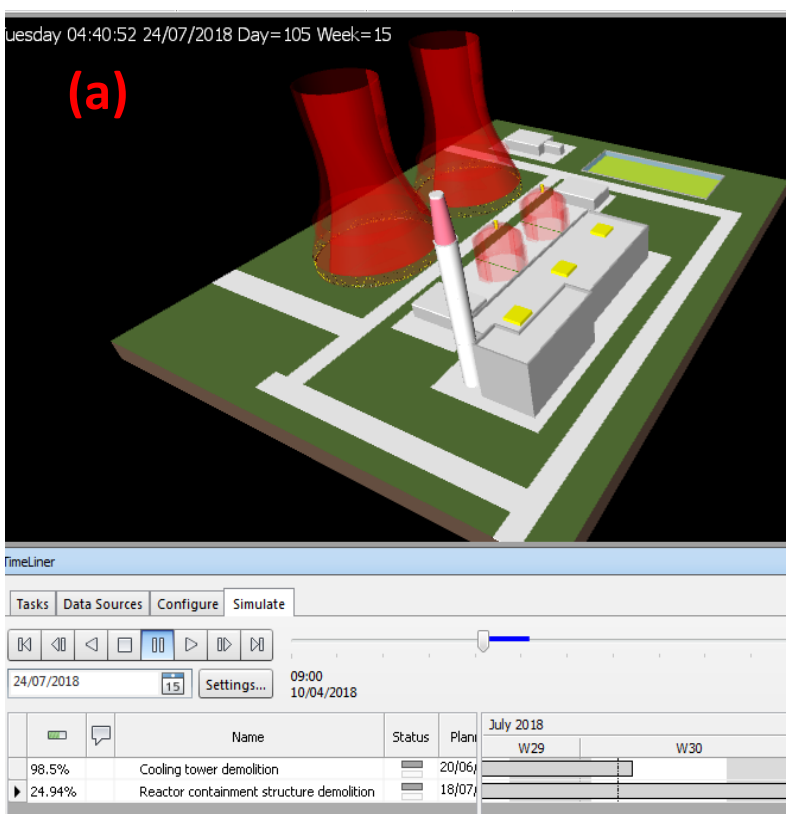

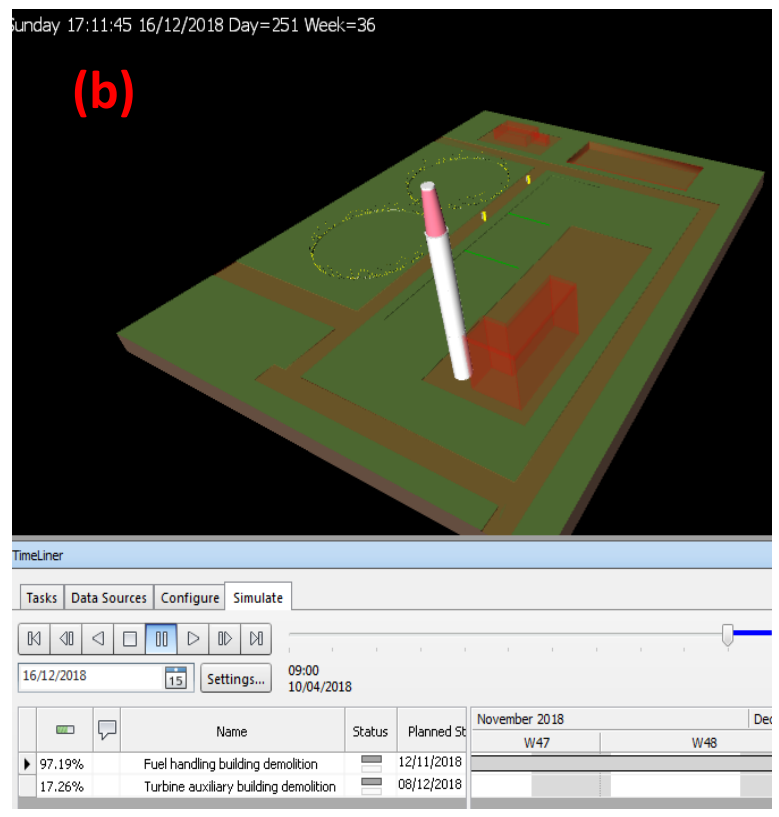

Figure 8: High-level simulation of the NPP decommissioning process 


\section{Implications of study and limitations}

Although the development of nuclear energy is highly demanding in terms of technological requirements, security and safety, costs and maintenance, it has continued to thrive amid alternative sources such as wind power. The development of nuclear energy has contributed significantly to maintaining continuous and stable electricity in at least 31 countries. These countries are distributed around five continents: Europe Asia, North America, South America and Asia with Europe and Asia having the greatest share. Nonetheless, the development of nuclear power, like other innovations, will continue to need refining and optimisation to drive better efficiencies in delivery, including costs savings, achieving better safety and protection of the environment. Hence, research such as developing a BIM-driven nuclear decommissioning framework to exploit emerging technological systems and processes is important in contributing to bridging existing gaps in digitalisation.

There has been a clamour for the digital transformation of existing assets, those being constructed and to be constructed in the future. However, the level of such transformation differs and should continue to grow positively with emerging research works and roadmaps. This is more likely to happen in a conducive atmosphere where there is good collaboration, complementary functioning and partnership between three key players: universities, research institutes and industry (Chen et al., 2017). While industry provides services, products and contexts for investigation/development, research institutes carry out innovative research targeted at specific science and technology needs; universities concentrate on educating and training personnel that will serve in those roles. The integrated nuclear digital framework proposed by Patterson et al (2016) is an example of using digital twins to manage operations in the nuclear industry, an approach commonly suggested in the digital transformation of assets (BSI, 2019). The proposed BIM-driven framework extends this concept to the actualisation of digitisation in implementing nuclear power plant decommissioning; harnessing information on regulations to inform the process. This work is based on a hypothetically 
modelled nuclear power plant demonstrating context-focussed access of regulation information to assist stakeholders during decommissioning as proof of concept. It suffices to mention that many currently operating nuclear power plants or those approaching decommissioning lack contemporary digital models, as BIM was non-existent when these plants were constructed and commissioned for commercial operation. One available means of recreating digital models of such nuclear plants incorporating refurbishments and modifications carried out over the life of the plant is through sophisticated laser scanner and point cloud acquisition processes as suggested in Volk et al (2019).

The vast number of rules and guidelines governing the development of NPP promote and ensure safety in the operation of nuclear power systems to the highest level possible. It is also important to make these rules and guidelines easily accessible to those who should put them into action either by observing them or ensuring others do. As expected, with such vast number of rules and guidelines associated with NPP decommissioning, it can be overwhelming to identify context-focused information for swift application in/on decommissioning tasks. Such challenges can be overcome by the proposed BIM-driven framework demonstrated from this research. As an implication for research, this study opens the area of exploring the fusing of textual information relating to administration, policies, and management to project models at different lifecycle stages of nuclear projects. This direction is possible due to the advent of BIM, of which the scope of application is ever-expanding. An example of such multidimensional expansion integrated into modelling of projects is proposed with the utilisation of lessons learned knowledge in BIM (Oti et al., 2018). The rules covered in this work are limited to maintenance rules, maintenance of the final safety analysis reports, fire safety requirements and actions by certified fuel handlers. Also, to demonstrate the concept reflected in the proposed framework, only the most relevant parts of the regulations have been captured in the work. Extending this work beyond the concept level to more comprehensive work will require dissecting the numerous rules and regulations for appropriate classification and mapping to all conventional decommissioning tasks. This will probably require the services of a 
multidisciplinary team of nuclear engineers, health and nuclear physicists and support of colleagues with legal backgrounds to validate that rules and regulations have been appropriately mapped.

\section{Conclusion}

Despite high security and safety requirements, the development of nuclear power stations is often a favoured part of the electric power generation mix. Nuclear power plants, when exploited safely, have relatively more environmentally friendly processes and systems. Nevertheless, the industry has continued to invest in research and development to further improve processes and systems for optimisation and the reduction of costs in associated project phases of design and construction, operation and decommissioning. The decommissioning process is governed by myriads of rules and regulations which are yet to be fully integrated into contemporary digital transformation processes. In fulfilling the objectives, this research established the need to integrate nuclear rules/regulations. BIM can be used for decommissioning, developing and implementing a framework for the contextfocused querying and linking of decommission rules/regulations and model items/tasks which was demonstrated by means of example cases. The proposed application of BIM methodology to explore context-focused information queries and activity sequencing to enhance the execution of decommissioning tasks vis-à-vis existing safety requirements and regulations is novel.

Many knowledge management systems are hinged on text-based query engines, which become less useful for the efficient retrieval of context-focused information in graphical environments to aid project delivery. It is proposed that using BIM technology to integrate decommissioning rules and regulations linked to the modelled elements and project tasks of nuclear power plant projects helps to improve delivery. The target is to help stakeholders contribute to the delivery of nuclear power generation projects overcome challenges, by accessing important rules and regulations as and when needed. The implementation relies on business processes to map/represent concepts, components 
and their respective relationships. Information on rules and regulations are hosted in a nonstructured query system (MongoDB) and interfaced with Navisworks Manage project management BIM tool. A model of a nuclear power plant was used to test the system. Results demonstrate that the myriads of rules and regulations guiding the development of nuclear plants can be integrated into BIM environments and used to inform decommissioning processes. The proposed system contributes to improving the convenience of stakeholders accessing context-focused rules and regulations and subsequent application in tackling decommissioning tasks. We therefore conclude that context-focused accessibility of rules and regulations can be integrated into nuclear decommissioning BIM environments to enhance delivery.

\section{References}

Abanda, F., Oti, A. and Tah, J. (2017). "Integrating BIM and new rules of measurement for embodied energy and $\mathrm{CO} 2$ assessment." Journal of Building Engineering 12: 288-305.

Abanda, F. H., Vidalakis, C., Oti, A. H. and Tah, J. H. M. (2015). "A critical analysis of Building Information Modelling systems used in construction projects." Advances in engineering software $\mathbf{9 0}$ 183-201.

Akbarnezhad, A., Ong, K. and Chandra, L. (2014a). "Economic and environmental assessment of deconstruction strategies using building information modeling." Automation in Construction 37: 131144.

Akbarnezhad, A., Ong, K. C. G. and Chandra, L. R. (2014b). "Economic and environmental assessment of deconstruction strategies using building information modeling." Automation in Construction 37: 131-144.

Autodesk (2018). Navisworks API Develpoers's Guide Autodesk Inc.

BEIS (2018). Industrial Strategy: Nuclear Sector Deal. Business Energy and Industrial Strategy. London, HM Government.

Bond, A., Palerm, J. and Haigh, P. (2004). "Public participation in EIA of nuclear power plant decommissioning projects: a case study analysis." Environmental Impact Assessment Review 24(6): 617-641.

Brook, B. W., Alonso, A., Meneley, D. A., Blees, J. T. and van Erp, J. B. (2014). "Why nuclear energy is sustainable and has to be part of the energy mix." Sustainable Materials and Technologies 1(2): 8-16.

BSI (2019). Transition guidance to BS EN ISO 19650 British Standards Institute. PD 19650-0:2019, British Standards Institution 2019, British Standards Institute. BS EN ISO 19650. 
Chen, K., Zhang, Y., Zhu, G. and Mu, R. (2017). "Do research institutes benefit from their network positions in research collaboration networks with industries or/and universities?" Technovation.

Cheng, J. C. and Ma, L. Y. (2013). "A BIM-based system for demolition and renovation waste estimation and planning." Waste Management 33(6): 1539-1551.

Chou, I.-H. and Fan, C.-F. (2006). "Developing integrated decommissioning information management system (IDIMS) of nuclear facilities." Journal of Nuclear Science and Technology 43(5): 596-604.

Cumo, M. (2002). Experiences and Techniques in the Decommissioning of Old Nuclear Power Plants. Workshop on Nuclear Reaction Data and Nuclear Reactors: Physics, Design and Safety.

DECC (2013). The United Kingdom's Sixth National Report on Compliance with the Convention on Nuclear Safety Obligations. Department of Energy and Climate Change, Crown

Di Gironimo, G., Labate, C. V., Renno, F., Siuko, M., Lanzotti, A. and Crisanti, F. (2014). "An interactive design approach for nuclear fusion purposes: remote handling system for FAST divertor." International Journal on Interactive Design and Manufacturing (IJIDeM) 8(1): 55-65.

EC Council Directive (1985). "Council Directive 85/337/EEC of 27 June 1985 on the assessment of the effects of certain public and private projects on the environment." Official Journal L 175(05/07): 0040-0048.

ENSREG, E. (2011). "Stress Test." Specifications, Annex I to the Declaration of ENSREG.

Ferrada, X., Sepúlveda, M., Serpell, A., Núñez, D. and Neyem, A. (2014). "A lessons-learned mobile system for construction companies: motivation and design." Procedia Engineering 85: 157-165.

HSE (2007). Guidance on the Nuclear Reactors (Environmental Impact Assessment for Decommissioning) Regulations, Health \& Safety Executive (HSE) Nuclear Directorate.

Hübner, F., Volk, R., Semme, J. and Schultmann, F. (2016). Improvement of nuclear decommissioning and dismantling planning via experience ex-change and optimisation methods. Proceedings of the 3rd Conference on Technological Innovations in Nuclear Civil Engineering, Paris, F, 5.-9. September 2016.

IAEA (2018). Nuclear Power Reactors in the World, Reference Data Series No. 2, 2018 edition,, International Atomic Energy Agency (IAEA).

Iguchi, Y., Kanehira, Y., Tachibana, M. and Johnsen, T. (2004). "Development of Decommissioning Engineering Support System (DEXUS of the Fugen Nuclear Power Station." Journal of Nnuclear Science and Technology 41(3): 367-375.

Ilhan, B. and Yaman, H. (2016). "Green building assessment tool (GBAT) for integrated BIM-based design decisions." Automation in Construction 70: 26-37.

Jeong, K., Choi, B., Moon, J., Hyun, D., Lee, J., Kim, I., Kim, G. and Kang, S. (2016). "Establishment of the hazard reduction methodology to be taken into account for safety assessment during decommissioning of nuclear facilities." Annals of Nuclear Energy 87: 7-15. 
Kim, Y., Kim, M. and Kim, W. (2013). "Effect of the Fukushima nuclear disaster on global public acceptance of nuclear energy." Energy Policy 61: 822-828.

Larsson, H., Anunti, A. and Edelborg, M. (2013). Decommissioning Study of Oskarshamn NPP. Westinghouse Electric Sweden AB.

Lu, R. Y., Karoutas, Z. and Sham, T.-L. (2011). "CASL virtual reactor predictive simulation: Grid-to-rod fretting wear." Jom 63(8): 53.

Matt, C., Hess, T. and Benlian, A. (2015). "Digital transformation strategies." Business \& Information Systems Engineering 57(5): 339-343.

NDA (2019). Understanding activities that produce radioactive wastes in the UK, Nuclear Decommissioning Authorty, UK Nuclear Decommissioning Authorty (NDA).

ONR (2019). Nuclear Safety Technical assessment guide - Decommissioning on Nuclear Licensed sites, NS-TAST-GD-026 R5 Office for Nuclear Regulation (ONR).

Oti, A., Tah, J. and Abanda, F. (2018). "Integration of Lessons Learned Knowledge in Building Information Modeling." Journal of Construction Engineering and Management 144(9): 04018081.

Patel, K. and McCarthy, M. P. (2000). Digital Transformation: the Essentials of E-business Leadership, McGraw-Hill Professional.

Patterson, E. A., Feligiotti, M. and Hack, E. (2013). "On the integration of validation, quality assurance and non-destructive evaluation." The Journal of Strain Analysis for Engineering Design 48(1): 48-58.

Patterson, E. A., Taylor, R. J. and Bankhead, M. (2016). "A framework for an integrated nuclear digital environment." Progress in Nuclear Energy 87: 97-103.

Pioro, I. I. and Duffey, R. R. (2015). "Nuclear Power as a Basis for Future Electricity Generation." ASME J of Nuclear Rad Sci. 1(1): 1-19.

Suh, Y. A., Hornibrook, C. and Yim, M.-S. (2018). "Decisions on nuclear decommissioning strategies: Historical review." Progress in Nuclear Energy 106: 34-43.

Tangkawarow, I. and Waworuntu, J. (2016). A Comparative of business process modelling techniques. IOP Conference Series: Materials Science and Engineering, IOP Publishing.

TEPC (2011). Fukushima Nuclear Accident Investigation Report (Interim Report - Supplementary Volume), The Tokyo Electric Power Company (TEPC), Inc.

USNRC (2000). Decommissioning of nuclear power reactors, Regulatory Guide 1.184. Office of Nuclear Regulatory Research, U.S. Nuclear Regulatory Commission (USNRC),

Vernikos, V. (2012). Optimising building information modelling and off-site construction for civil engineering. Proceedings of the Institution of Civil Engineers-Civil Engineering, Thomas Telford Ltd.

Volk, R., Hübner, F., Hünlich, T. and Schultmann, F. (2019). "The future of nuclear decommissioningA worldwide market potential study." Energy Policy 124: 226-261. 
WNA (2019). "Plans For New Reactors Worldwide, World Nuclear Association (WNA)." Retrieved January, 2019, from http://world-nuclear.org/information-library/current-and-futuregeneration/plans-for-new-reactors-worldwide.aspx.

Yanagihara, S. (1993). "COSMARD: The code system for management of JPDR decommissioning." Journal of Nuclear Science and Technology 30(9): 890-899.

Yanagihara, S., Sukegawa, T. and Shiraishi, K. (2001). "Development of computer systems for planning and management of reactor decommissioning." Journal of Nuclear Science and Technology 38(3): 193-202. 